\title{
Cerebral Glucose Hypermetabolism in Friedreich's Ataxia Detected with Positron Emission Tomography
}

\author{
Sid Gilman, MD, ${ }^{*}$ Larry Junck, MD, ${ }^{*}$ Dorene S. Markel, MS, ${ }^{*}$ Robert A. Koeppe, PhD, $\dagger$ \\ and Karen J. Kluin, MSł
}

\begin{abstract}
Local cerebral metabolic rate for glucose was studied with ${ }^{18} \mathrm{~F}$-2-fluoro-2-deoxy-D-glucose and positron emission tomography (PET) in 22 patients with Friedreich's ataxia and 23 age-matched normal control subjects. The diagnosis of Friedreich's ataxia was established by the history and physical findings and by excluding other diseases through laboratory investigations. PET studies revealed a statistically significant widespread increase of local cerebral metabolic rate for glucose in the brains of patients with Friedreich's ataxia who were still ambulatory, in comparison with normal control subjects. Nonambulatory patients with Friedreich's ataxia, in comparison with normal control subjects, had significantly increased local cerebral metabolic rates for glucose in the caudate and lenticular nuclei, but not in the other structures studied. The rate was significantly greater in ambulatory patients with Friedreich's ataxia than in nonambulatory patients in all structures studied except the caudate and lenticular nuclei. The data suggest that early in the course of Friedreich's ataxia, the local cerebral metabolic rate for glucose is increased extensively in the central nervous system, and as the disease progresses, it decreases in a regionally specific manner.
\end{abstract}

Gilman S, Junck L, MarkeI DS, Koeppe RA, Kluin KJ. Cerebral glucose hypermetabolism in Friedreich's ataxia detected with positron emission tomography. Ann Neurol 1990;28:750-757

Friedreich's ataxia (FA) is a chronic progressive neurological disorder inherited as an autosomal recessive trait with the abnormal gene located on chromosome 9 [1-6]. The disorder usually begins before puberty with progressive ataxia of gait and muscle weakness. As these symptoms worsen, other disturbances appear and include: limb ataxia; dysarthria; scoliosis; pes cavus; loss of position sense, vibration sense, and light touch sensation of the limbs; loss of the deep tendon reflexes; and the appearance of extensor plantar responses [1-4]. Nearly all patients eventually require a wheelchair because of progressive weakness and ataxia of the legs. A cardiomyopathy occurs and usually accounts for death by middle age [7]. Some patients with FA develop diabetes mellitus [5].

The principal neuropathological changes in FA involve the peripheral nerves and the spinal cord $\lfloor 1$, 4, 8-11]. Degeneration occurs in peripheral sensory nerves, dorsal root ganglia, and dorsal roots. Within the spinal cord, there is degeneration of posterior columns, lateral corticospinal tracts, and dorsal and ventral spinocerebellar tracts. The cerebellum and brainstem have been described as normal [11], but in some patients there is shrinkage of the pons and medulla [9, 10]. Occasional parients show patchy atrophy of the Purkinje cells, and in many there is degeneration of neurons in the dentate nuclei [10]. Degenerative changes may also occur in the reticular and vestibular nuclei of the brainstem $[9,10]$.

Many biochemical abnormalities have been reported in fibroblasts, leukocytes, or muscle tissue from patients with $F A$, but some of these findings are controversial. Deficiencies in activity of the pyruvate dehydrogenase complex and alpha ketoglutarate dehydrogenase complex have been described [12, 13]. Other abnormalities reported include deficiency of mitochondrial malic enzyme activity $[14,15]$ and of serum lipoprotein lipase [16] and abnormalities of erythrocyte membrane phospholipids, plasma catecholamines, and leukocyte glutamate dehydrogenase activity [5].

In most patients with $F A$, the characteristic history and physical findings make the diagnosis relatively straightforward [1-4]. In patients with progressive ataxia whose history and physical findings differ from those typical of FA, however, the diagnosis is often
From the Departments of *Neurology, $\uparrow$ Internal Medicine, and $¥$ Physical Medicine and Rehabilitation, The University of Michigan, Ann Arbor, MI.

Received Feb 21, 1990, and in revised form Jun 11. Accepted for publication Jun $17,1990$.
Address correspondence to Dr Gilman, The University of Michigan, Department of Neurology, 1914/0316 Taubman Center, 1500 E. Medical Center Drive, Ann Arbor, MI 48109-0316. 
difficult and requires extensive laboratory testing. The differential diagnosis of these patients includes malformations, degenerations, demyelinative diseases, neoplasms, remote effects of neoplasms, vascular diseases, and metabolic abnormalities $[1,17]$.

Positron emission tomography (PET) with ${ }^{18} \mathrm{~F}-2-$ fluoro-2-deoxy-D-glucose $\left({ }^{18} \mathrm{~F}-\mathrm{FDG}\right)$ has been used to study local cerebral metabolic rate for glucose (1CMRglc) in the central nervous system of patients with olivopontocerebellar atrophy, another degenerative disease causing ataxia [18-20]. A distinctive pattern of hypometabolism was found in the brainstem and cerebellum without involvement of the cerebral cortex, basal ganglia, or thalamus. The present study was undertaken to determine whether a unique pattern might be found in patients with FA as well. Degeneration of spinocerebellar afferents, which terminate in the granule cell layer of the vermis [1], might be expected to result in cerebellar hypometabolism principally within vermal regions. In addition, degeneration of second-order sensory neurons originating in the gracile and cuneate nuclei as well as transynaptic effects from degeneration of first-order sensory neurons $[9,11]$ might be expected to result in loss of synapses and hypometabolism in the thalamus. Surprisingly, the results of this study demonstrated widespread cerebral hypermetabolism in patients with FA who were still ambulatory, with metabolic rates close to normal control levels in patients with $\mathrm{FA}$ who were no longer ambulatory. Preliminary descriptions of this work have been published [21-24\}.

\section{Materials and Methods}

We studied 22 patients with FA and 23 normal control subjects (Table 1 ). The studies were approved by the institutional review board, and informed consent was obtained from all subjects. Among the patients with $\mathrm{FA}$, the duration of illness averaged $18 \pm 7$ years and ranged from 6 to 30 years. Ten patients had one or more affected siblings, 11 had no affected relatives, and 1 patient had a cousin who may have FA. The normal control subjects had no history of neurological disease and no significant abnormalities on neurological and general physical examination. The patients and normal control subjects were taking no medication known to affect central nervous system (CNS) function or to cause CNS side effects and subjects with a history of alcoholism were excluded.

The diagnosis of FA was made on the basis of the history, physical examination, neurological examination, and laboratory tests to exclude other diseases. Required findings included ataxia of limb movements and of gait if the patients were still ambulatory; weakness of the lower extremities; ataxic dysarthria; decreased or absent muscle stretch reflexes in the lower extremities; extensor plantar reflexes; and decreased position and vibration sense in the lower extremities. The diagnosis was supported by the findings of scoliosis, pes cavus, decreased pinprick and light touch sensation in the distal parts of the extremities, and atrophy of the distal limb
Table 1. Average Ages of the Subjects Studied

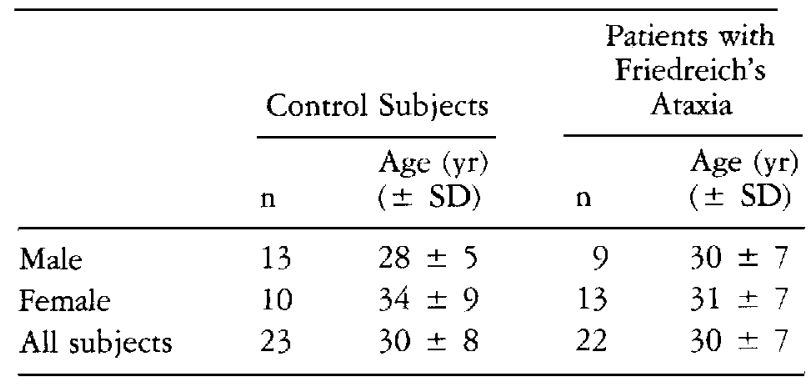

muscles. All patients met the diagnostic criteria of Harding [2]. All patients also met the criteria of Geoffroy and colleagues [25] except one whose age at onset (23 years) is above their limit of 20 years; elimination of this patient from the analysis did not substantially alter the findings of this study. Patients with an atypical history or examination were excluded from the study before their data were analyzed. The patients excluded were a 28 -year-old man who had preserved position sense and vibration sense in the legs, a 49year-old man who had intact deep tendon reflexes in the legs, and a 30-year-old woman who did not have dysarthria. Analyses of duration of illness excluded 6 patients who were not the first member of their family diagnosed with FA, to avoid the bias that may be introduced in determining disease onset when another family member has been previously diagnosed with FA.

PET studies of normal control subjects and patients with FA were performed with the subjects lying supine, awake, immobile, not speaking, and blindfolded in a quiet room. They were maintained under these conditions from $5 \mathrm{~min}-$ utes before injection until completion of the scan. ${ }^{18} \mathrm{~F}-\mathrm{FDG}$ was synthesized by an adaptation of the method of Shiue and associates [26] or of Hamacher and coworkers [27]. Radiochemical purity was greater than $95 \%$. Scans were performed 30 to 75 minutes after intravenous injection of 5 to $10 \mathrm{mCi}$ of ${ }^{18} \mathrm{~F}$-FDG and lasted for 8 to 12 minutes. Each subject was placed in a headholder that maintained the head immobile throughout the study. The head was aligned along the orbitomeatal line with a laser. PET scans were performed with a TCC PCT 4600 A tomograph having an inplane resolution of $11-\mathrm{mm}$ full width at half maximum (FWHM) and a Z-axis resolution of 9.5-mm FWHM. Five planes with 11.5$\mathrm{mm}$ center-to-center separation were imaged simultaneously. Four sets of scans were taken per patient, including two interleaved sets through lower brain levels and two interleaved sets through higher brain levels for a total of 20 slices, each separated by $5.75 \mathrm{~mm}$. Attenuation correction was calculated by fitting ellipses to the contour of the scalp outline and modified to account for attenuation from the headholder and skull. Blood samples were collected from one radial artery. ICMRglc was calculated with a three compartment model and single-scan approximation, with gray matter kinetic constants derived from normals.

Regions of interest (ROIs) were studied in the cerebral cortex, basal ganglia, thalamus, cerebellar hemispheres, cerebellar vermis, mesencephalon, and pons. Data from the cerebral cortex were obtained by measuring $1 \mathrm{CMRglc}$ in the cortical rim from six consecutive slices beginning with the 
Table 2. Local Cerebral Metabolic Rate for Glucose (in $\mathrm{mg} / 100 \mathrm{gm} / \mathrm{min}$ ) in All Subjects $\mathrm{s}^{\mathrm{a}}$

\begin{tabular}{llll}
\hline Structure & Control Subjects $(\mathbf{n}=23)$ & $\begin{array}{l}\text { Patients with } \\
\text { Friedreich's Ataxia }(\mathrm{n}=22)\end{array}$ & 0 Value \\
\hline Cerebral cortex & $5.80 \pm 1.07$ & $6.64 \pm 1.30$ & 0.02 \\
Caudate nucleus & $6.20 \pm 1.32$ & $7.91 \pm 1.56$ & 0.0003 \\
Lenticular nucleus & $6.82 \pm 1.44$ & $8.10 \pm 1.64$ & 0.008 \\
Thalamus & $6.81 \pm 1.46$ & $7.29 \pm 1.87$ & $\mathrm{NS}$ \\
Cerebellar vermis & $5.10 \pm 1.05$ & $5.55 \pm 1.33$ & $\mathrm{NS}$ \\
Left cerebellar hemisphere & $5.59 \pm 1.20$ & $6.04 \pm 1.61$ & $\mathrm{NS}$ \\
Right cerebellar hemisphere & $5.47 \pm 1.18$ & $6.10 \pm 1.66$ & $\mathrm{NS}$ \\
Mesencephalon & $5.06 \pm 1.02$ & $5.54 \pm 1.21$ & $\mathrm{NS}$ \\
Pons & $4.10 \pm 0.79$ & $4.46 \pm 1.05$ & $\mathrm{NS}$ \\
\hline
\end{tabular}

${ }^{a}$ Values given are the mean $\pm \mathrm{SD}$; statistical test, Student's $t$ test.

NS $=$ not significant; $p>0.10$.

lowest slice containing the basal ganglia. This was accomplished with an algorithm that detects the outer edge of the cortical rim on images that have been passed through a contrast-enhancing filter. The algorithm then identifies a cortical strip on the original image that extends inward from this edge until either the metabolic rate drops below the value on the outer edge of the rim or the strip reaches a width of 15 $\mathrm{mm}$. The mean metabolic rate was computed for each of the ROIs and the final value was a weighted mean of the values from the six individual slices. The ROIs for the basal ganglia consisted of an $11 \times 11-\mathrm{mm}$ square on each side of the caudate nucleus and an $11 \times 15-\mathrm{mm}$ parallelogram on each side of the lenticular nucleus (putamen and globus pallidus). The other ROIs consisted of an $11 \times 11-\mathrm{mm}$ square on each side of the thalamus, a $22 \times 11-\mathrm{mm}$ parallelogram on each cerebellar hemisphere, and an $11 \times 18-\mathrm{mm}$ rectangle on the cerebellar vermis. For analysis of the mesencephalon and pons, a three-dimensional image set consisting of planes spaced at $3.75 \mathrm{~mm}$ intervals in the rostrocaudal direction was generated by interpolation of the two-dimensional images. A midsagittal image, $11 \mathrm{~mm}$ in thickness, was derived from this image set. The resulting volume of interest for the mesencephalon was an $11 \times 11 \times 7.5-\mathrm{mm}$ right parallelepiped, while that for the pons was a $15 \times 11 \times 15-\mathrm{mm}$ right parallelepiped. The ROIs were centered over a local peak in ICMRgic. For reference, an individual image element (pixel) is $3.75 \times 3.75 \mathrm{~mm}$ in size. Data were obtained from two slices containing the cerebellum and brainstem, from one slice containing the thalamus, and from one slice containing the basal ganglia. ROIs from the cerebellar vermis were posterior to the fourth ventricle, as determined by direct visualization of the ventricle.

An index of brain volume was developed to compare the patients with FA and the control subjects. The mean crosssectional area of the brain from the two largest adjacent PET slices was measured, and this value was raised to the $3 / 2$ power.

Statistical analysis was performed with two-tailed Student's $t$ tests, analysis of variance, the Newman-Keuls test, and Spearman rank correlation analysis. A $p$ value of 0.05 or less was taken as significant.
Table 3. Comparison of Ambulatory and Nonambulatory Patients with Friedreicb's Ataxia

\begin{tabular}{llll}
\hline & Ambulatory & Nonambulatory & $p$ Value \\
\hline Age $^{\mathrm{b}}$ & $30 \pm 7$ & $30 \pm 7$ & NS \\
$\begin{array}{c}\text { Age of onset } \\
(\mathrm{yr})^{c}\end{array}$ & $17 \pm 4$ & $10 \pm 4$ & 0.007 \\
\begin{tabular}{c} 
Duration $(\mathrm{yr})^{\mathrm{c}}$ \\
\hline
\end{tabular} & $15 \pm 5$ & $21 \pm 5$ & 0.08 \\
\hline
\end{tabular}

${ }^{a}$ Values given are the mean $\pm \mathrm{SD}$; statistical test, Student's $t$ test. $\mathrm{b}_{\mathrm{n}}=8$ ambulatory, 14 nonambulatory patients.

$c_{n}=5$ ambulatory, 11 nonambulatory patients (only first patients: affected in a family are included).

$\mathrm{NS}=$ not significant; $p=0.95$.

\section{Results}

Mean 1CMRglc for the entire FA group was $7 \%$ to $28 \%$ greater than that of the control group for the structures analyzed. Statistical testing revealed significantly increased ICMRglc in the patients with FA, compared with the control subjects, in the cerebral cortex, caudate nucleus, and lenticular nucleus, but not in the thalamus, cerebellar vermis, cerebellar hemispheres, or brainstem (Table 2).

To examine the relationship between the severity of the neurological disorder and ICMRglc, we divided the patients into two groups, ambulatory and nonambulatory. The two groups were equal in age at the time of the study, but the ambulatory patients had a significantly later age of onset than did the nonambulatory patients (Table 3). Mean ICMRglc for the ambulatory group was $23 \%$ to $34 \%$ greater than that of the control group for the structures analyzed (Table 4, Fig 1). ICMRglc in the ambulatory group was significantly increased, compared with the normal control subjects, in all structures studied except the pons. In contrast, mean ICMRglc for the nonambulatory group ranged 
Table 4. Local Cerebral Metabolic Rate for Glucose (in mg/100 gm/min) in Control Subjects and Ambulatory and Nonambulatory Patients with Friedreich's Ataxia $(F A)^{a}$

\begin{tabular}{lllllll}
\hline & $\begin{array}{l}\text { Control } \\
\text { Subjects } \\
(\mathrm{n}=23)\end{array}$ & $\begin{array}{l}\text { Ambulatory } \\
\text { Patients } \\
\text { with FA } \\
(\mathrm{n}=8)\end{array}$ & $p$ Value $^{\mathrm{b}}$ & $\begin{array}{l}\text { Nonambulatory } \\
\text { Patients } \\
\text { with FA } \\
(\mathrm{n}=14)\end{array}$ & $p$ Value $^{\mathrm{c}}$ & $p$ Value $^{\mathrm{d}}$ \\
Structure & $5.80 \pm 1.07$ & $7.24 \pm 0.80$ & 0.01 & $6.29 \pm 1.42$ & $\mathrm{NS}$ & 0.07 \\
Cerebral cortex & $6.20 \pm 1.32$ & $8.30 \pm 1.23$ & 0.002 & $7.68 \pm 1.72$ & 0.005 & $\mathrm{NS}$ \\
Caudate nucleus & $6.82 \pm 1.44$ & $8.51 \pm 1.53$ & 0.03 & $7.86 \pm 1.71$ & 0.03 & $\mathrm{NS}$ \\
Lenticular nucleus & $6.81 \pm 1.46$ & $8.58 \pm 1.43$ & 0.007 & $6.55 \pm 1.71$ & $\mathrm{NS}$ & 0.01 \\
Thalamus & $5.10 \pm 1.05$ & $6.28 \pm 0.79$ & 0.04 & $5.13 \pm 1.41$ & $\mathrm{NS}$ & 0.03 \\
Cerebellar vermis & $5.59 \pm 1.20$ & $7.09 \pm 1.03$ & 0.007 & $5.45 \pm 1.61$ & $\mathrm{NS}$ & 0.02 \\
Left cerebellar hemisphere & $5.47 \pm 1.18$ & $7.17 \pm 1.02$ & 0.008 & $5.49 \pm 1.67$ & $\mathrm{NS}$ & 0.006 \\
Right cerebellar hemisphere & $5.06 \pm 1.02$ & $6.22 \pm 0.93$ & 0.03 & $5.15 \pm 1.20$ & $\mathrm{NS}$ & 0.03 \\
Mesencephalon & $4.10 \pm 0.79$ & $5.09 \pm 0.67$ & 0.07 & $4.10 \pm 1.07$ & $\mathrm{NS}$ & 0.03 \\
Pons & & & & & &
\end{tabular}

${ }^{a}$ Values given are the mean $\pm S D$; statistical test, Newman-Keuls.

${ }^{b}$ Comparison of normal control subjects with ambulatory patients with FA.

'Comparison of normal control subjects with nonambulatory patients with FA.

${ }^{d}$ Comparison of ambulatory with nonambulatory patients with $\mathrm{FA}$.

$\mathrm{NS}=$ not significant; $p>0.20$.

from $4 \%$ less to $24 \%$ greater than that of the normal control group for the structures analyzed. ICMRglc was significantly higher in nonambulatory patients than in normal controls for the basal ganglia, but not for the other structures (see Table 4). ICMRgk was significantly greater in the ambulatory patients than in the nonambulatory group in all structures studied except for the cerebral cortex, where the difference approached significance, and in the basal ganglia (see Table 4). The differences between control, ambulatory, and nonambulatory groups are portrayed in Figure 2 , in which the data in the two FA groups are normalized to the values of the control group.

To determine whether differences in ICMRglc between the sexes contributed to the observed differences between groups, we compared lCMRglc in patients with FA and normal control subjects using analysis of variance with sex and disease group as factors (Table 5). The results revealed that sex was not a significant factor for any region. Disease group was a significant factor for the cerebral cortex, caudate nucleus, and lenticular nucleus, but not for the thalamus, cerebellum, or brainstem. There was no significant interaction between disease group and sex for ICMRglc values from any region.

Since FA is a progressive disorder, we examined ICMRglc as a function of age and duration of symptoms. ICMRglc declined significantly with increasing age in the caudate nucleus (Spearman rank correlation coefficient $r_{s}=-0.46, p=0.03$ ) and lenticular nucleus $\left(r_{\mathrm{s}}=-0.48, p=0.02\right)$, but lCMRglc did not correlate significantly with age for the other brain regions analyzed $\left(r_{\mathrm{s}}=-0.29\right.$ to $\left.-0.08, p>0.20\right)$.
ICMRglc did not correlate with duration of symptoms for any region $\left(r_{\mathrm{s}}=-0.33\right.$ to $\left.+0.06, p>0.20\right)$ in the 16 patients who were the first in the family to develop the disease.

Patients with FA are thought to have an increased incidence of diabetes mellitus [5], and elevation of the plasma glucose level could influence measurements of ICMRglc in the CNS. Only 1 patient, who was nonambulatory, had diabetes mellitus, and his fasting blood glucose was elevated $(326 \mathrm{mg} / 100 \mathrm{dl})$. His 1 CMRglc values averaged approximately one standard deviation (SD) above the mean of the nonambulatory group. If this patient's results were eliminated, the data presented in Tables 2 and 4 would change little, and all significant results in these tables would remain significant. Mean fasting blood glucose levels were $87 \pm 8$ $\mathrm{mg} / \mathrm{dl}$ (mean $\pm \mathrm{SD}$ ) in the normal control group and $86 \pm 8 \mathrm{mg} / \mathrm{dl}$ in the FA group, excluding the diabetic parient.

The brain volumes of the patients with $F A$ were compared with those of the normal control subjects. In the patients with $\mathrm{FA}(\mathrm{n}=22)$, the mean volume index was $2,080 \pm 157 \mathrm{~cm}^{3}$, whereas in the normal controls $(\mathrm{n}=23)$, the mean volume index was $2,269 \pm 230$ $\mathrm{cm}^{3}$. These values are significantly different $(t=3.22$, $p<0.003$ ). This difference was found in both males and females (male $\mathrm{FA}: \mathbf{n}=9,2,176 \pm 159 \mathrm{~cm}^{3}$, versus male control subjects: $\mathbf{n}=13,2,390 \pm 210$ $\mathrm{cm}^{3}, t=2.59, p=0.02$; female FA: $\mathrm{n}=13,2,013 \pm$ $118 \mathrm{~cm}^{3}$, versus female control subjects: $\mathrm{n}=10$, $\left.2,111 \pm 146 \mathrm{~cm}^{3}, t=1.78, p=0.09\right)$. The mean volume index for the ambulatory patients with $F A$ $\left(\mathrm{n}=8,2,081 \pm 175 \mathrm{~cm}^{3}\right)$ was not significantly differ- 


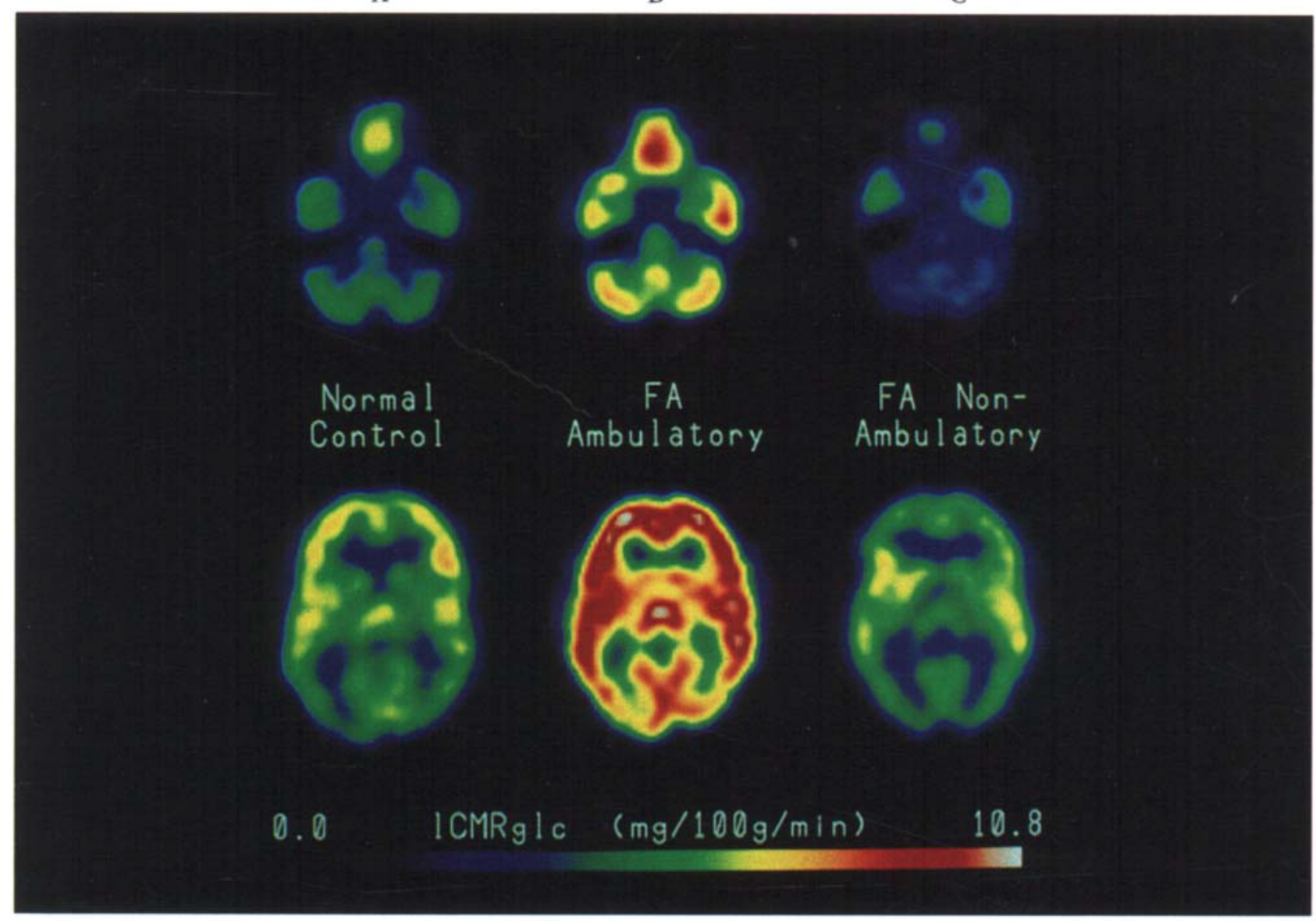

$\mathrm{D}$

Fig 1. PET scans showing cerebral glucose utilization as detected witb ${ }^{18}$ F-2-furoro-2-deoxy-D-glucose. Scans in A, B, and C show $a$ borizontal section at the level of the cerebellum and the base of the temporal and frontal lobes. Scans in D, E, and F show the Level of the basal ganglia and thalamus. Color bars indicate the rate of glucose utilization $(\mathrm{mg} / 100 \mathrm{gm} / \mathrm{min})$. (A and D) Control subject, female, age 24 years. (B and E) Ambulatory patient with Friedreich's ataxia, female, age 25 years. ( $C$ and $F$ )

Nonambulatory patient witb Friedreich's ataxia, female, age 29 years. Note the glucose bypermetabolism in the ambulatory patient with Friedreich's ataxia compared with the control subject and the nonambulatory patient with Friedreich's ataxia.

ent from the mean volume index for the nonambulatory patients with FA ( $\mathbf{n}=14,2,079 \pm 151 \mathrm{~cm}^{3}, t=$ $0.02, p>0.5)$.

\section{Discussion}

This study provided evidence of cerebral glucose hypermetabolism extensively in the CNS of patients with FA who are still ambulatory in comparison with ageand sex-matched normal control subjects. Significantly increased ICMRglc also was found in nonambulatory patients with FA in comparison with normal control subjects, but only within the basal ganglia. Ambulatory

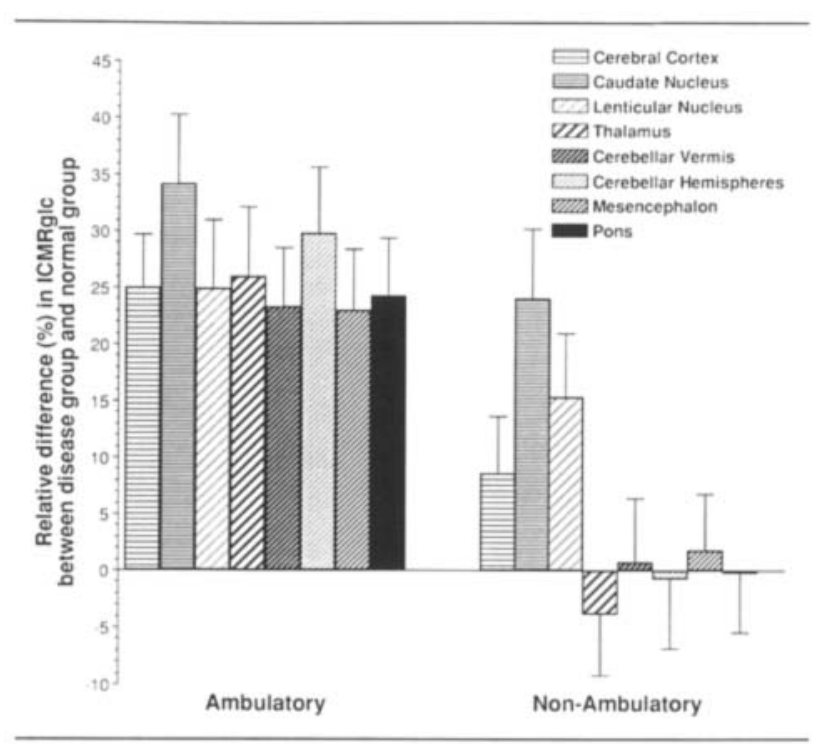

Fig 2. Mean local cerebral metabolic rate for glucose (lCMRglc) relative to the values of the normal control subjects for ambulatory and nonambulatory patients with Friedreich's ataxia. Error bars represent the standard error of the mean. 
Table 5. Local Cerebral Metabolic Rate for Glucose (in $\mathrm{mg} / 100 \mathrm{gm} / \mathrm{min}$ ) in Males and Females ${ }^{a}$

\begin{tabular}{llllll}
\hline Structure & $\begin{array}{l}\text { Male Control } \\
\text { Subjects } \\
(\mathrm{n}=13)\end{array}$ & $\begin{array}{l}\text { Female Control } \\
\text { Subjects } \\
(\mathbf{n}=10)\end{array}$ & $\begin{array}{l}\text { Male Patients } \\
\text { with FA }^{\mathrm{b}} \\
(\mathbf{n}=9)\end{array}$ & $\begin{array}{l}\text { Female Patients } \\
\text { with FA } \\
(\mathbf{n}=13)\end{array}$ & $p$ Value $^{\mathrm{b}}$ \\
\hline Cerebral cortex & $5.54 \pm 0.92$ & $6.14 \pm 1.21$ & $6.42 \pm 1.07$ & $6.79 \pm 1.45$ & 0.04 \\
Caudate nucleus & $5.92 \pm 1.17$ & $6.56 \pm 1.47$ & $7.60 \pm 1.40$ & $8.12 \pm 1.68$ & 0.0006 \\
Lenticular nucleus & $6.50 \pm 1.24$ & $7.23 \pm 1.64$ & $7.95 \pm 1.42$ & $8.20 \pm 1.83$ & 0.014 \\
Thalamus & $6.24 \pm 1.03$ & $7.54 \pm 1.67$ & $6.90 \pm 1.45$ & $7.55 \pm 2.12$ & NS \\
Cerebellar vermis & $4.75 \pm 0.87$ & $5.56 \pm 1.13$ & $5.37 \pm 1.06$ & $5.67 \pm 1.51$ & NS \\
Left cerebellar hemisphere & $5.26 \pm 1.08$ & $6.01 \pm 1.27$ & $5.66 \pm 1.11$ & $6.31 \pm 1.88$ & NS \\
Right cerebellar hemisphere & $5.13 \pm 1.08$ & $5.91 \pm 1.20$ & $5.67 \pm 1.17$ & $6.40 \pm 1.91$ & NS \\
Mesencephalon & $4.63 \pm 0.72$ & $5.62 \pm 1.10$ & $5.37 \pm 1.09$ & $5.65 \pm 1.31$ & NS \\
Pons & $3.88 \pm 0.69$ & $4.39 \pm 0.86$ & $4.28 \pm 0.97$ & $4.58 \pm 1.12$ & NS \\
\hline
\end{tabular}

aalues given are the mean $\pm \mathrm{SD}$; statistical test, analysis of variance with disease group and sex as factors.

bex is not a significant factor for any region.

' $p$ Value: disease as factor (comparison of disease group for male and female normal control subjects versus male and female patients with FA).

$\mathrm{FA}=$ Friedreich's ataxia; NS $=$ not significant,$p>0.20$.

patients had significantly higher lCMRglc than nonambulatory patients for all structures except the basal ganglia. Neither the sexes nor the ages of the patients was a significant factor in the findings.

The age of onset of symptoms was significantly greater in patients who were ambulatory at the time of the study than in the nonambulatory patients. This difference is most likely explained on the basis of selection bias. Age 18 was the minimum age at which normal control subjects and patients were eligible for our study in accordance with institutional policy regarding studies with radionuclides in children. In a slowly progressive disease such as FA, patients who remain ambulatory over the age of 18 are likely to be those with a late age of onset. It may also be that our ambulatory patients had intrinsically milder disease or slower progression of disease than our nonambulatory patients. We cannot exclude the possibility that our group of ambulatory patients represents, in part, a different phenotype from the nonambulatory group. Variations in phenotype are known to occur even in kindreds that inherit the same abnormal gene $[8,25,28,29]$.

Our findings may indicate that, early in the course of FA, glucose metabolic rate is increased broadly in the $\mathrm{CNS}$, and as the disease progresses, metabolic rate decreases. The decrease is nonuniform, with the basal ganglia maintaining a higher metabolic rate with disease progression than the other structures studied. The increased metabolism may reflect a fundamental biochemical defect in FA, while the decline in metabolic rate with disease progression may be due to loss of neurons and synaptic terminals. This would explain the finding of more substantially increased metabolic rate in ambulatory than in nonambulatory patients, since typically with disease progression, FA patients lose the ability to walk.
The possibility that the finding of glucose hypermetabolism is artifactual must be considered. The major potential sources of error are FA-specific alterations in ${ }^{18} \mathrm{~F}-\mathrm{FDG}$ rate constants between subject groups, and smaller brain size in patients with FA than in normal control subjects. The possibility that FAspecific alterations in the rate constants affected our data seems unlikely, since changes in rate constants that cause major errors in the single-scan approximation used to evaluate ICMRglc have not been found in any progressive degenerative neurological disease. We found that patients with FA have smaller brain volumes than normal control subjects; however, this finding is not likely to account for the glucose hypermetabolism. Hatazawa and colleagues [30] found in normal subjects that ICMRglc is inversely proportional to brain volume. Since the small brain volume in patients with FA presumably results from their disease process, it is questionable whether the same relationship applies to them. This relationship clearly does not apply to patients with Alzheimer's disease, who have a decreased volume associated with hypometabolism. Even if this relationship were to apply to patients with $\mathrm{FA}$, the $7 \%$ decrease in brain volume compared to normal subjects would account for only a $7 \%$ increase in 1 CMRglc, yet we observed a $23 \%$ to $34 \%$ increase in ICMRglc in ambulatory patients with FA, compared with normal subjects.

The demonstration of CNS glucose hypermetabolism in patients with FA might be explained by abnormalities of carbohydrate metabolism in this disease [31]. Many patients with FA have been found to have difficulty with the metabolism of pyruvate [32-34]. Following a glucose load, patients with FA typically have elevated blood pyruvate levels [13], and pyruvate clearance is delayed [34]. The precise defect in FA 
responsible for abnormalities of carbohydrate metabolism is controversial. Deficiencies of the pyruvate dehydrogenase complex, alpha ketoglutarate, and mitochondrial malic enzyme in FA have been found in some laboratories $[12,15,35-37]$ but not in others [32, 38-40]. Perhaps some of the discrepancies in findings relate to the stage of the disease in which the patients' tissues are examined or to different phenotypes of the disease.

Blass and associates [31] suggested that the characteristic biochemical abnormality in FA and related conditions results from damage to mitochondria rather than deficiency of a specific mitochondrial enzyme. Damaged mitochondria may explain some of the controversial biochemical findings $[31,41]$. Mitochondrial abnormalities have been invoked to explain much of the pathophysiology of this disease $[30,33]$ and a mitochondrial disorder could explain the findings in the present study. Glucose hypermetabolism may reflect a needed increase in glycolytic rate because of difficulty in the oxidation of pyruvate to enter the Krebs tricarboxylic acid cycle. Future studies of the mitochondrial abnormalities in FA should take into account the stage of the disease process or the phenotypic expression of the disease since our study suggests that the abnormalities may change with progression of the disease.

We cannot exclude the possibility that an increased value for the lumped constant for fluorodeoxyglucose in FA could partially or completely account for our finding of increased ICMRglc values, which were calculated assuming a normal value for the lumped constant (0.51). An increase in the lumped constant for 2-deoxyglucose has been described in hypoglycemia $[42,43]$ and is thought to be due to a shift in the ratelimiting step from phosphorylation to transport. Conceivably, an increased value of the lumped constant in FA could share the same mechanism. Alterations in the lumped constant could influence our findings in either of two possible ways. First, the lumped constant could be increased in patients with early disease and could then decline with disease progression. This possibility is unlikely because changes that may occur with disease progression, such as loss of neurons and synaptic connections, would not be expected to reverse the change in the lumped constant substantially. Second, the lumped constant could be increased in all patients with FA, and the decrease in lCMRglc values in nonambulatory patients compared with ambulatory patients could represent a true decline in glucose metabolism associated with loss of neuronal elements.

The difference in metabolism between ambulatory and nonambulatory patients may be due to loss of neuronal connections as the disease progresses. Study of the degree of atrophy in ambulatory as compared with nonambulatory patients in anatomical scans would perhaps clarify this issue. The findings of glucose hy- permetabolism within certain structures in ambulatory but not in nonambulatory patients resulted from examining a cross-section of patients. Our speculation that glucose metabolism decreases with progression of FA may be strengthened by longitudinal follow-up of individual patients with repeated testing. We have not studied patients with FA early in the disease process because our PET studies are limited to patients and normal subjects age 18 and older. From our present results, we cannot determine whether patients early in the course of FA have a greater degree or a lesser degree of hypermetabolism than our ambulatory group, most of whom are at an intermediate stage of the disease with a moderate level of disability. Similarly, our data do not make clear whether metabolism declines to a level below that of normal subjects. Examination of patients with FA toward the end of their disease process would be necessary to establish this.

In previous PET studies, the finding of glucose hypermetabolism in steady state is unusual. Increased glucose metabolism has been reported in Down's syndrome [44, 45], anorexia nervosa [46], and autism [47], but in a recent report no definitive evidence of increased metabolism was found in autism [48], and the finding in Down's syndrome is now thought to be artifactual [49]. Thus, FA is one of only a few conditions demonstrated through PET to involve hypermetabolism in steady state.

Supported in part by National Institutes of Health grant NS 15655 .

We are indebted to the staff of the Division of Nuclear Medicine for their assistance in this project.

\section{References}

1. Gilman S, Bloedel JR, Lechtenberg R. Disorders of the cerebellum. Philadelphia: Davis, 1981

2. Harding AR. Friedreich's ataxia: a clinical and genetic study of 90 families with an analysis of early diagnostic criteria and intrafamilial clustering of clinical features. Brain 1981;104:589620

3. Harding AR. The hereditary ataxias and related disorders. London: Churchill-Livingstone, 1984

4. Tyrer JH. Friedreich's ataxia. In: Vinken PJ, Bruyn GW, eds. Handbook of clinical neurology, vol 21. Amsterdam: NorthHolland, 1975:319-364

5. Stumpf DA. The inherited ataxias. Neurol Clin 1985;2:47-57

6. Chamberlain S, Shaw J, Rowland A, et al. Mapping of mutation causing Friedreich's ataxia to human chromosome 9. Nature 1988;334:248-250

7. Heiver RL. The heart in Friedreich's ataxia. Br Heart J 1969;31:5-14

8. Greenfield JG. The spinocerebellar degenerations. Blackwell: London, 1954

9. Oppenheimer DR. Brain lesions in Friedreich's ataxia. Can J Neurol Sci 1979;6:173-176

10. Oppenheimer DR. Diseases of the basal ganglia, cerebellum and motor neurons. In: Hume Adams J, Corsellis JAN, Duchen LW, eds. Greenfield's neuropathology. 4th ed. Wiley: New York, 1984:699-747 
11. Lamarche JP, Lemieux B, Lieu HB. The neuropathology of "typical" Friedreich's ataxia in Quebec. Can J Neurol Sci 1984;11:592-600

12. Blass JP, Kark RAP, Menon NK. Low activities of the pyruvate and oxoglutarate dehydrogenase complexes in five patients with Friedreich's ataxia. N Engl J Med 1976;295:62-67

13. Kark RAP, Blass JP, Engel WK. Pyruvate oxidation in neuromuscular diseases: evidence of a genetic defect in two families with the clinical syndrome of Friedreich's ataxia. Neurology 1974;24:964-971

14. Stumpf DA, Parks JK, Eguren LA, Haas R. Friedreich ataxia. III. Mitochondrial malic enzyme deficiency. Neurology 1982; 32:221-227

15. Bottachi E, DiDonato S. Skeletal muscle $\mathrm{NAD}^{+}(\mathrm{P})$ and $\mathrm{NADP}^{+}$-dependent malic enzyme in Friedreich's ataxia. Neurology 1983;33:712-716

16. Blache D, Bouthillier D, Barbeau A, Davignon J. Plasma lipoprotein lipase and hepatic lipase activities in Friedreich's ataxia. Can J Neurol Sci 1982;9:191-194

17. Gilman S. Inherited ataxia. In: Johnson RT, ed. Current therapy in neurologic disease, vol 2. Toronto: Decker, 1987:224-232

18. Gilman S, Markel DS, Koeppe RA, et al. Cerebellar and brainstem hypometabolism in olivopontocerebellar atrophy detected with positron emission tomography. Ann Neurol 1988;23:223230

19. Kluin KJ, Gilman S, Markel DS, et al. Speech disorders in olivopontocerebellar atrophy correlate with positron emission tomography findings. Ann Neurol 1988;23:547-554

20. Rosenthal G, Gilman S, Koeppe RA, et al. Motor dysfunction in olivopontocerebellar atrophy is relared to cerebral metabolic rate studied with positron emission tomography. Ann Neurol $1988 ; 24: 414-419$

21. Gilman S, Junck L, Markel DS, et al. Cerebellar and thalamic hypometabolism in Friedreich's ataxia studied with PET. Neurology 1988;38:366

22. Gilman S, Junck L, Markel DS, et al. Cerebral glucose hypermetabolism in Friedreich's ataxia studied with positron emission tomography. J Cereb Blood Flow Metab 1989;9:\$19

23. Gilman S. Cerebellar diseases: studies with positron emission tomography. Semin Neurol 1989;9:376-382

24. Gilman S. Positron emission tomography studies of the cerebellar degenerations. In: Plaitakis A, ed. Cerebellar degenerations: clinical neurobiology. Norwell: Nijhoff, 1991 (in press)

25. Geoffroy G, Barbeau A, Breton G, et al. Clinical description and roentgenologic evaluation of patients with Friedreich's ataxia. Can J Neurol Sci 1976;3:279-286

26. Shive C-Y, Salvadori PA, Wolf AP, et al. A new improved synthesis of 2 -deoxy-2- $\left[{ }^{18} \mathrm{~F}\right]$ fluoro-D-glucose from ${ }^{18} \mathrm{~F}$-labeled acetyl hypofluorite. J Nucl Med 1982;23:899-903

27. Hamacher $\mathrm{K}$, Coenen $\mathrm{HH}$, Stocklin G. Efficient stereospecific synthesis of NCA 2-[18 F]-fluoro-2-deoxy-D-glucose using aminopolyether supported direct nucleophilic substitution. J Nucl Med 1986;27:235-238

28. Blass JP. Hereditary ataxias. In: Appel SH, ed. Current neurology, vol 3. Wiley: New York, 1981:66-91

29. Cedarbaum JM, Blass JP. Mitochondrial dysfunction and spinocerebellar degenerations. Neurochem Pathol 1986;4:43-63
30. Hatazawa J, Brooks RA, DiChiro G, Campbell G. Global cerebral glucose utilization is independent of brain size: a PET study. J Comput Assist Tomogr 1987;11:571-576

31. Blass JP, Sheu RK-F, Cedarbaum JM. Energy metabolism in disorders of the nervous system. Rev Neurol (Paris) 1988; 144:543-563

32. Barbeau A, Butterworth RF, Ngo T, et al. Pyruvate metabolism in Friedreich's ataxia. Can J Neurol Sci 1976;3:379-388

33. Barbeau A. Friedreich's disease 1982: etiologic hypotheses. A personal analysis. Can J Neurol Sci 1982;9:243-256

34. Dijkstra U, Gabreels F, Joosten E, et al. Friedreich's ataxia: intravenous pyruvate load to demonstrate a defect in pyruvate metabolism. Neurology 1984;34:1493-1497

35. Bertagnolio B, Uziel G, Bottachi E, et al. Friedreich's ataxia. II. Biochemical studies in cultured cells. Ital J Neurol Sci 1980; 1:239-243

36. Kark RAP, Budelli MM, Becker DM, et al. Lipoamide dehydrogenase: rapid heat inactivation in platelets of patients with recessively inherited ataxia. Neurology 1981;31:199-201

37. Stumpf DA, Parks JK, Parker WD. Friedreich's disease. IV. Reduced mitochondrial malic enzyme activity in heterozygotes. Ann Neurol 1983;33:780-783

38. Constantopoulos G, Chang CSC, Barranger JA. Normal pyruvate dehydrogenase complex activity in patients with Friedreich's ataxia. Ann Neurol 1980;8:636-638

39. Stumpf DA, Parks JK. Friedreich's ataxia. II. Normal kinetics of lipoamide dehydrogenase. Neurology 1979;29:802-826

40. Chamberlain S, Lewis PD. Normal mitochondrial malic enzyme levels in Friedreich's ataxia fibroblasts. J Neurol Neurosurg Psychiatry 1983;47:1050-1051

41. Constantopoulos G, Greenwood MA, Sorrell SH. Mitochondrial abnormalities in fibroblast line GM3093, defective in oxidative metabolism. Experientia 1986;42:315-318

42. Crane PD, Pardridge WM, Braun LD, et al. Kinetics of transport and phosphorylation of 2-fluoro-2-deoxy-D-glucose in rat brain. J Neurochem 1983;40:160-167

43. Mori K, Cruz N, Dienel G, et al. Direcr chemical measurement of the $\mathrm{k}$ of the lumped constant of the $\left[{ }^{14} \mathrm{C}\right]$ deoxyglucose method in rat brain: effects of arterial plasma glucose level on the distribution space of $\left[{ }^{14} \mathrm{C}\right]$ deoxyglucose and glucose and on k. J Cereb Blood Flow Metab 1989;9:304-314

44. Schwartz M, Duara R, Haxby J, et al. Down's syndrome in adults: brain metabolism. Science 1983;221:781-783

45. Schapiro MB, Haxby JV, Grady CL, et al. Decline in cerebral glucose utilisation and cognitive function with aging in Down's syndrome. J Neurol Neurosurg Psychiatry 1987;50:766-774

46. Herholz K, Krieg JC, Emrich HM. Regional cerebral glucose metabolism in anorexia nervosa measured by positron emission tomography. Biol Psychiatry 1987;22:43-51

47. Rumsey JM, Duara R, Grady C, et al. Brain metabolism in autism. Arch Gen Psychiatry 1985;42:448-455

48. De Volder A, Bol A, Michel C, et al. Brain glucose metabolism in children with the autistic syndrome: positron emission tomography analysis. Brain Dev 1987;9:581-587

49. Schapiro MB, Grady CL, Kumar A, et al. Regional cerebral glucose is normal in young adults with Down syndrome. J Cereb Blood Flow Metab 1990;10:199-206 